\title{
DNA Damage Response in Prostate Cancer
}

\author{
Matthew J. Schiewer ${ }^{1,5}$ and Karen E. Knudsen ${ }^{1,2,3,4,5}$ \\ ${ }^{1}$ Department of Cancer Biology, Thomas Jefferson University, Philadelphia, Pennsylvania,19107 \\ ${ }^{2}$ Department of Medical Oncology, Thomas Jefferson University, Philadelphia, Pennsylvania 19107 \\ ${ }^{3}$ Department of Urology, Thomas Jefferson University, Philadelphia, Pennsylvania 19107 \\ ${ }^{4}$ Department of Radiation Oncology, Thomas Jefferson University, Philadelphia, Pennsylvania 19107 \\ ${ }^{5}$ The Sidney Kimmel Cancer Center at Thomas Jefferson University, Philadelphia, Pennsylvania 19107 \\ Correspondence: karen.knudsen@jefferson.edu
}

Prostatic adenocarcinoma (PCa) remains a significant health concern. Although localized PCa can be effectively treated, disseminated disease remains uniformly fatal. PCa is reliant on androgen receptor (AR); as such, first-line therapy for metastatic PCa entails suppression of AR signaling. Although initially effective, recurrent tumors reactivate AR function, leading to a lethal stage of disease termed castration-resistant PCa (CRPC). Recent findings implicate AR signaling in control of DNA repair and show that alterations in DNA damage repair pathways are strongly associated with disease progression and poor outcome. This review will address the DNA repair alterations observed in the clinical setting, explore the anticipated molecular and cellular consequence of DNA repair dysfunction, and consider clinical strategies for targeting tumors with altered DNA repair.

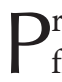
ostatic adenocarcinoma $(\mathrm{PCa})$ is the most frequently diagnosed noncutaneous malignancy in men in the United States, and the third leading cause of cancer death in U.S. men (Siegel et al. 2017). Although organ-confined disease can be readily managed (Lavery and Cooperberg 2017), there is no durable means of treatment for advanced, disseminated PCa (Cotter et al. 2016; Ritch and Cookson 2016). First-line therapy for metastatic disease targets the androgen receptor (AR) signaling axis via androgen deprivation therapy (ADT), as PCa is typically dependent on the action of AR for cell survival and proliferation. However, within 3-4 years of initiating therapy, patients relapse, and the AR signaling pathway is reactivated despite continued therapeutic targeting. For this stage of disease, deemed castrate-resistant PCa (CRPC), there are no durable therapeutic options (Ferraldeschi et al. 2015; Saad and Fizazi 2015; Coutinho et al. 2016; Graham and Schweizer 2016).

Recent findings indicate that, although recurrent copy number changes occur in $\mathrm{PCa}$, point mutations in early-stage $\mathrm{PCa}$ are less frequent (Taylor et al. 2010; Grasso et al. 2012; Cancer Genome Atlas Research 2015; Tomlins et al. 2015). In advanced disease, the frequency of point mutations and widespread genomic rearrangements is further enhanced (Kumar et al. 2011a,b, 2016; Grasso et al. 2012; Beltran et al. 2013, 2017; Robinson et al. 2015b; Pritchard et al. 2016). For example, no single gene in non-

Editors: Michael M. Shen and Mark A. Rubin

Additional Perspectives on Prostate Cancer available at www.perspectivesinmedicine.org

Copyright (C) 2019 Cold Spring Harbor Laboratory Press; all rights reserved; doi: 10.1101/cshperspect.a030486

Cite this article as Cold Spring Harb Perspect Med 2019;9:a030486 
indolent localized PCa is mutated in $>10 \%$ of tumors (Barbieri et al. 2012; Cancer Genome Atlas Research 2015; Fraser et al. 2017b); however, it has been reported that an excess of CRPC tumors harbor potentially actionable mutations (Robinson et al. 2015b). As such, CRPC biology is markedly distinct from that of localized PCa following selective adaptation driven by ADT. Despite a paucity of mutations present in localized $\mathrm{PCa}$, it has been observed that primary $\mathrm{PCa}$ harbors both copy number alterations and recurrent genomic rearrangements (Taylor et al. 2010; Berger et al. 2011; Kumar et al. 2011a,b, 2016; Barbieri et al. 2012; Grasso et al. 2012; Beltran et al. 2013, 2017; Cancer Genome Atlas Research 2015; Robinson et al. 2015a; Tomlins et al. 2015; Fraser et al. 2017a). Furthermore, PCa harbors a significant number of genomic rearrangements that have the potential to be derived in an interdependent manner leading to rapid, punctuated evolution of $\mathrm{PCa}$ in a phenomenon termed chromoplexy (Baca et al. 2013; Imielinski and Rubin 2017). This chromoplexy can result in coordinated disruption of multiple cancer genes and may result from open chromatin and active transcription by factors such as AR (Berger et al. 2011).

As will be discussed herein, clinical observations have revealed significant enrichment of alterations in DNA repair processes as a function of disease progression, suggesting that DNA repair defects may be selected for as a mechanism of therapeutic bypass. Furthermore, cross talk between the AR pathway and DNA repair components has been identified and shown to have relevance for disease management. The impact of DNA repair alterations, AR-DNA repair cross talk, and the potential to convert knowledge of these processes into novel modes of clinical intervention will be considered.

\section{OVERVIEW OF DNA DAMAGE AND REPAIR PATHWAYS}

DNA damage is a major contributor to carcinogenesis (Bartkova et al. 2005). Although the genome is replicated with high fidelity in normal cells, with only one error in $\sim 1 \times 10^{10}$ bases replicated (McCulloch and Kunkel 2008), a number of sources contribute to the formation of genetic lesions that can lead to carcinogenesis. Exogenous sources of DNA damage include toxins, ultraviolet (UV) radiation, mutagenic chemicals, and ionizing radiation. Mutations can result from endogenous damage as well (Tubbs and Nussenzweig 2017), and reactive oxygen species (ROS) and reactive nitrogen species (NOS) released from immune cells can induce oxidative damage within the prostatic epithelia (Colotta et al. 2009; Jaamaa and Laiho 2012). Additionally, ROS can be generated as a byproduct of normal cellular metabolism (Tennant et al. 2009). Regardless of the source of DNA damage, failure of proper DNA repair or the use of error-prone repair results in sustained genetic alterations that include base oxidation and alkylation, interstrand cross-linking, UV photoproducts, and adduct formation, as well as single-strand breaks (SSBs) or double-strand breaks (DSBs). To maintain genomic integrity and to suppress tumorigenesis, the process of evolution has selected for a system to repair DNA damage termed DNA damage response and repair (DDR) (Bartkova et al. 2005; Bartek et al. 2007). DDR encompasses the detection of the damage, engagement of cell cycle checkpoints, induction and recruitment of repair factors to the site of the lesion, and subsequent repair of the damage. Effective damage repair results in reengagement of the cell cycle, although improper repair or damage at a level that overwhelms the system results in permanent cell cycle exit (senescence) or apoptotic cell death. One of the hallmarks of cancer, genomic instability, results when cells are not able to properly repair damage, yet survive (Hanahan and Weinberg 2011).

To resolve damaged DNA, eukaryotic cells possess a number of disparate DNA pathways with unique capabilities that have been reviewed extensively elsewhere (Ceccaldi et al. 2015; Abbotts and Wilson 2016; Bhattacharjee and Nandi 2016; Hustedt and Durocher 2016; Jeggo et al. 2016; Roos et al. 2016; Williams and Schumacher 2016; Brown et al. 2017). In brief, base excision repair (BER) is responsible for the removal of small lesions that do not distort the double helix, such as oxidized bases or misincorporated uracil. Bulky DNA adducts are re- 
paired by the nucleotide excision repair (NER), although base mismatches/insertions-deletions are repaired via mismatch repair (MMR). Mammalian cells typically repair DSBs via homologous recombination (HR) or nonhomologous end joining (NHEJ) (Ceccaldi et al. 2015; Ermolaeva et al. 2015). DSBs present after DNA replication can be repaired via the high-fidelity HR pathway, owing to the requirement for a template (sister chromatid) for this DSB repair mechanism. In all other phases of the cell cycle, NHEJ and related mechanisms are engaged to repair DSBs, but these processes are errorprone. Alterations in DDR pathway integrity, such as germline or somatic mutation, promoter methylation of key genes, or other epigenetic alterations, increase susceptibility to malignant transformation. As discussed below, alterations in each of these pathways have been shown to increase PCa risk and/or are associated with disease progression.

\section{DNA REPAIR ALTERATIONS AND PCa RISK}

Preliminary findings have implicated alterations in DNA repair pathways as being associated with risk of PCa development, aggressiveness, and progression. Single-nucleotide polymorphisms (SNPs) in several DNA damage repair pathway genes have been reported with increased risk of $\mathrm{PCa}$, including BER (Mittal et al. 2012), NER (Mittal and Mandal 2012; Yang et al. 2013; Mirecka et al. 2014; Wang et al. 2016), MMR (Saunders et al. 2016; Scarbrough et al. 2016), NHEJ (Chang et al. 2008; Mandal et al. 2011; Henriquez-Hernandez et al. 2016), HR (Scarbrough et al. 2016), and the DNA damage-related kinase ATM (Angele et al. 2004). Although these studies provide evidence that SNPs in DDR genes are associated with increased PCa risk (summarized in Fig. $1 \mathrm{~A}$ ), their use is limited by a lack of functional studies and data on causation. Additional analyses of SNPs and risk alleles is needed to assess which genetic alteration(s) are likely actionable.

Despite current limitations for implementing overall SNP-associated alleles in PCa screening, diagnosis, and management, several studies indicate that germline mutations in DNA repair genes may demark biologically distinct PCa cases. A large cohort of men with multiple familial PCa diagnoses $(n=191)$ were sequenced for 22 tumor suppressor genes, and the data show that loss-of-function mutations in these genes occurred with an approximate rate of $7 \%$, and these mutations were predictive of lymph node involvement, increased stage, and development of metastases (Leongamornlert et al. 2014). These data indicate that heritable DNA repair defects predispose to poor outcomes in PCa. A second large study $(n=692)$ of men with metastatic PCa that examined 20 genes involved in autosomal dominant cancer predisposition syndromes found that almost $12 \%$ of these cases harbored germline DDR gene defects, which was much higher than that observed in primary PCa (4.6\%, $n=499)$ (Pritchard et al. 2016). These studies (summarized in Fig. 1B) indicate that germline DNA repair defects may lead to tumor phenotypes distinct from those associated with sporadic cases. Concordantly, studies examining distinct DNA repair pathways reveal increasing evidence that heritable mutations in MMR genes predispose to $\mathrm{PCa}$, some of which are associated with Lynch syndrome (Grindedal et al. 2009; Pritchard et al. 2014; Ryan et al. 2014; Dominguez-Valentin et al. 2016). Further, data suggest that MMR defective tumors have a hypermutated and microsattelite unstable phenotype (Pritchard et al. 2014). Based on these data and the high frequency of PCa diagnoses annually (an estimated 161,360 in 2017 in the United States alone), DNA repair deficiency is linked to a large number of patients and should therefore be considered when making disease management decisions.

Further studies examining distinct DNA repair pathways show that heritable mutations in HR genes are associated with PCa risk, progression, therapeutic response, and outcomes. These include BRIP1 (Kote-Jarai et al. 2009), CHK2, and NBS1, the latter of which is prognostic for aggressive disease (Cybulski et al. 2013). Furthermore, germline $B R C A 1 / 2$ mutations are associated with aggressive disease (Gallagher et al. 2010) including nodal involvement and development of metastases (Castro et al. 2013). These mutations are putatively loss-of-function, 
M.J. Schiewer and K.E. Knudsen

A

\begin{tabular}{|c|c|c|c|}
\hline \multicolumn{4}{|c|}{ SNPs and PCa } \\
\hline Pathway & Genes(s) & Significance & Citation(s) \\
\hline BER & $X R C C 1$ & $\rightarrow$ Elevated risk & Mittal et al. 2012 \\
\hline NER & $\begin{array}{l}X P C \\
X P D \\
X P G \\
C S B\end{array}$ & $\rightarrow$ Elevated risk & $\begin{array}{c}\text { Mittal et al. } 2012 \\
\text { Yang et al. } 2013 \\
\text { Mirecka et al. } 2014 \\
\text { Wang et al. } 2016\end{array}$ \\
\hline MMR & MSH5 & $\rightarrow$ Elevated risk & $\begin{array}{l}\text { Saunders et al. } 2012 \\
\text { Scarbrough et al. } 2016\end{array}$ \\
\hline \multirow[t]{2}{*}{ HR } & $\begin{array}{l}R A D 51 B \\
B R C A 2\end{array}$ & $\rightarrow$ Elevated risk & $\begin{array}{l}\text { Saunders et al. } 2012 \\
\text { Scarbrough et al. } 2016\end{array}$ \\
\hline & $X R C C 4$ & $\rightarrow$ Elevated risk & $\begin{array}{l}\text { Chang et al. } 2008 \\
\text { Mandal et al. } 2011\end{array}$ \\
\hline NHEJ & $\begin{array}{c}\text { XRCC6 } \\
\text { MVP }\end{array}$ & $\rightarrow$ Aggressive $\mathrm{PCa}$ & Henrique-Hernandez et al. 2016 \\
\hline
\end{tabular}

C

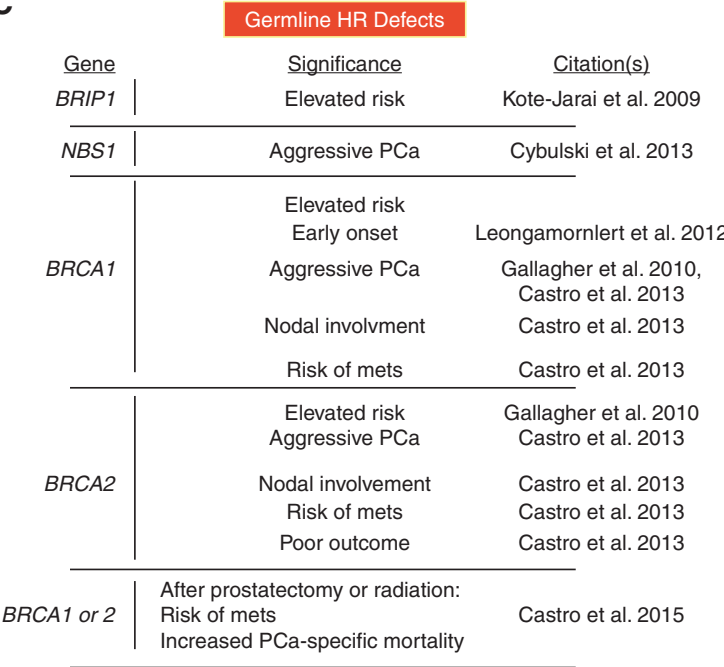

B

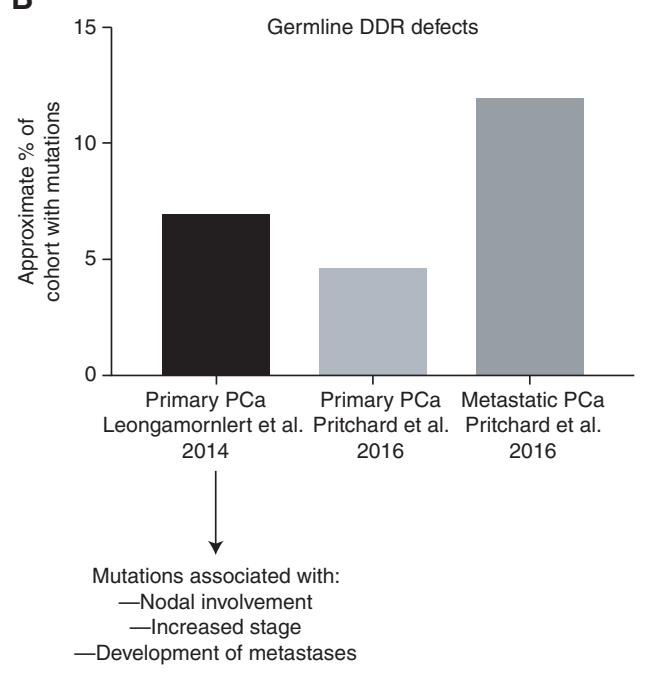

Figure 1. Single-nucleotide polymorphisms (SNPs) and germline DNA damage response and repair (DDR) mutations in prostate cancer. (A) SNPs that result in elevated risk for prostate cancer or disease aggressiveness have been identified in several studies (citations at right). These include SNPs in base excision repair (BER), nucleotide excision repair (NER), mismatch repair (MMR), homologous recombination (HR), and nonhomologous end joining (NHEJ). (B) Two studies have identified the prevalence of germline mutations in DDR genes. In primary prostate cancer $(\mathrm{PCa}), \sim 5 \%-7 \%$ of tumors are associated with germline DDR mutations (Leongamornlert et al. 2014; Pritchard et al. 2016). These germline DDR mutations were further found to be associated with lymph node involvement, higher disease stage, and increased frequency of metastases (Leongamornlert et al. 2014). Furthermore, in metastatic PCa, the prevalence of germline DDR mutations is higher than in primary $\mathrm{PCa}$ $(\sim 12 \%)$ (Pritchard et al. 2016). (C) Several studies (citations at right) have implicated germline HR mutations in significantly altering PCa biology. mets, metastases.

which would predict for defective HR. Heritable $B R C A 1$ alterations correlate with early-onset PCa (Leongamornlert et al. 2012), and aberrant $B R C A 1 / 2$ is associated with poor outcomes after curative treatment (prostatectomy or radiation) in primary disease (Castro et al. 2015). Finally, $B R C A 2$ mutations result in more aggressive primary disease that harbors other genetic defects that are typically more associated with metastatic disease although still localized in the prostate 
(Taylor et al. 2017). Based on the critical role BRCA2 plays in HR, these tumors are likely HR-defective, and this HR deficiency appears to be associated with aggressive disease. Together, these data (summarized in Fig. 1C) suggest that germline defects in multiple DDR genes predispose to PCa development, progression, and poor clinical outcomes.

\section{AR-DNA REPAIR CROSS TALK: IMPLICATIONS FOR LOCALLY ADVANCED DISEASE AND BEYOND}

Understanding of DNA repair function in $\mathrm{PCa}$, and the potential influence on risk and progression, was further advanced by discovery of major cross talk pathways linking AR function to DNA repair competency (Goodwin et al. 2013; Polkinghorn et al. 2013; Tarish et al. 2015). The concept that hormones regulated DNA repair was first observed in the clinical setting in the context of locally advanced PCa, which is defined as PCa that has extended beyond the prostatic and is locally invasive, but without local lymph node involvement or distant metastases. For locally advanced PCa, the standard of care is radiation therapy in conjunction with $\mathrm{ADT}$ based on significant survival benefits seen in large phase 3 clinical trials (Bolla et al. 1997, 2013; Widmark et al. 2009; Warde et al. 2011), including most recently the phase 3 RTOG 9601 (Shipley et al. 2017). RTOG 9601 analyzed the use antiandrogen therapy in 760 patients with localized disease treated with surgery followed by radiation therapy after 12 years of follow-up. The results indicate that the use of antiandrogens increased overall survival $(76.3 \%$ vs. $71.3 \%)$, decreased the incidence of metastases $(14.5 \%$ vs. $23 \%)$, and reduced PCa-specific death (5.8\% vs. $13.4 \%)$. Despite the overwhelming clinical evidence of the benefit of combined targeting $\mathrm{AR}$ and radiation, and the fact that $\mathrm{ADT}$ plus radiation therapy remains the standard of care for locally advanced PCa, the molecular underpinnings of sensitization to DNA damage by blocking AR function was ill-defined.

Mechanistic understanding of the means by which castration and/or AR-directed therapeutics enhance response to radiotherapy was recently attained through a series of seminal discoveries (Al-Ubaidi et al. 2013; Goodwin et al. 2013; Polkinghorn et al. 2013). In model systems of PCa, ADT enhances the antitumor effect of radiation, as is observed clinically. Interestingly, DNA damage induces AR transcriptional activity, and this DNA damage-induced AR activity is required for faithful DSB repair. Mechanistically, AR directly regulates the expression and function of DNA-PC catalytic subunit (DNAPKcs), which is a required component of NHEJ. Importantly, androgen-dependent DNA repair requires DNA-dependent kinase catalytic subunit (DNAPKcs) (Goodwin et al. 2013), indicating that the AR-DNAPKcs axis is a key determinant of radiosensitization by ADT. Additionally, AR regulates the expression of genes involved in HR (XRCC2, XRCC3 [Goodwin et al. 2013], RAD54B, and RAD51C [Polkinghorn et al. 2013]), as well as genes involved in DNA damage sensing, MMR, Fanconi anemia, and BER (especially poly(ADP-ribose) polymerase [PARP]-1) (Polkinghorn et al. 2013). Importantly, the impact of AR on expression of DNA repair genes was determined to be independent of its function in cell cycle progression and was instead a result of direct regulation of DDR gene transcription by AR. Accordingly, tissues from men with PCa having undergone ADT before prostatectomy have significantly decreased levels of Ku70 protein, a key component of the NHEJ pathway (Al-Ubaidi et al. 2013). As such, it is clear in both preclinical models and in human PCa tissues that a major function for $\mathrm{AR}$ is to regulate the expression and/or function of DNA repair genes, and that this AR-DNA repair cross talk is the underlying mechanism by which ADT cooperates with radiation in locally advanced $\mathrm{PCa}$.

Further exploration of AR-DNA repair cross talk led to new understanding of DNAPKcs function, linking this DNA repair-associated kinase to metastasis (Goodwin et al. 2015). Unbiased transcriptional profiling shows that DNAPKcs regulates a distinct gene expression signature in models of CRPC, including genes involved in androgen metabolism (UGTs, uridine $5^{\prime}$-diphospho-glucuronosyltransferases) and metastases such as PREX1, ROCK2, ITGB4, 
and VAV3. As such, DNAPKcs function supports metastatic phenotypes, including migration/invasion and developments of metastases in vivo. Clinically, DNAPKcs is the most deregulated kinase in a large cohort of localized PCa with significant follow-up, and high DNAPKcs proved independently predictive for biochemical recurrence, poor freedom from metastases, and poor overall survival. Importantly, DNAPKcs activity is significantly higher in metastatic CRPC than in treatment-naive PCa, independent of DNA damage, indicating DNAPKcs function is likely a key driver of PCa progression. Based on these data, the first-in-man DNAPKcs inhibitor (CC-115, a dual DNAPKcs/TOR inhibitor) is currently under clinical investigation in CRPC in combination with the AR antagonist enzalutamide (NCT02833883). These findings nominate DNAPKcs, induced downstream from $\mathrm{AR}$, as a biomarker to predict development of metastatic disease, and as a target for therapeutic intervention

Although DNAPK appears to be a clinically relevant DNA repair protein functioning directly downstream from AR, DNA repair factors also appear to function upstream of $\mathrm{AR}$ to influence AR signaling. Activation of several nuclear receptors, including $A R$, are associated with DNA DSBs (Ju et al. 2006), and AR activation in conjunction with exogenous DNA damage is associated with generation of DSBs that induce genomic rearrangements with PCa relevance, including TMPRSS2:ETS fusions (Tomlins et al. 2005; Lin et al. 2009; Mani et al. 2009; Haffner et al. 2010). The TMPRSS2:ETS fusions place ETS oncogenic transcription factors under control of AR by placing the coding region of ETS genes downstream from the AR-driven TMPRSS2 gene promoter via genomic rearrangement (Gasi Tandefelt et al. 2014). Whether this translocation occurs in the absence of exogenous DNA damage remains to be determined. Chromosome conformation capture $(\mathrm{Hi}-\mathrm{C})$ data indicate that overexpression of ERG places the regulatory loci of TMPRSS2 and $E R G$ in proximity (Rickman et al. 2012). Together, these data suggest that the oncogenic transcription factor functions of both AR and ERG may drive genomic rearrangements in PCa.
It has been shown that PARP-1/2 inhibition (PARPi) has significant benefit in patients with metastatic CRPC, and that responsive tumors are enriched for DDR defects (Mateo et al. 2015). However, in addition to being a key orchestrator of DNA repair, PARP-1 holds another important role on chromatin, namely transcriptional regulation. PARP-1 also functions as a transcriptional regulator in malignancy (reviewed in Schiewer and Knudsen 2014). Furthermore, there is preclinical evidence that PARP-1 regulates the transcriptional function of ETS transcription factors, and that elevated ETS function is associated with increased DNA DSBs in the absence of exogenous DNA damage, which can be reduced by PARPi (Brenner et al. 2011). Additionally, in the context of PCa, PARP- 1 positively regulates AR activity, as PARPi results in diminished AR chromatin residency, and subsequent decreased $A R$ target gene expression. The combination of ADT and PARPi in vivo results in a delay of the development castration resistance and enhanced tumor stasis in CRPC (Schiewer et al. 2012). The clinical relevance of PARP$1 / A R$ transcriptional regulation remains to be determined.

On balance, these findings show that interplay between AR and the DNA repair machinery, as depicted in Figure 2, has significant impact on tumor progression, and nominate DNA repair processes as targets for therapeutic intervention.

\section{DNA REPAIR ALTERATIONS ASSOCIATED WITH DISEASE PROGRESSION}

Given the impact of DNA repair functions on genome stability and AR function, it is perhaps expected that DNA repair alterations would be selected for during disease progression. Indeed, recent genome-wide analyses of human cancers strongly support a potential role for DNA repair pathway defects in promoting aggressive cancer features and therapeutic relapse.

\section{DNA Repair Alteration in Primary PCa}

The Cancer Genome Atlas (TCGA) recently sought to integrate data from multiple omics 
DNA Damage Response in Prostate Cancer

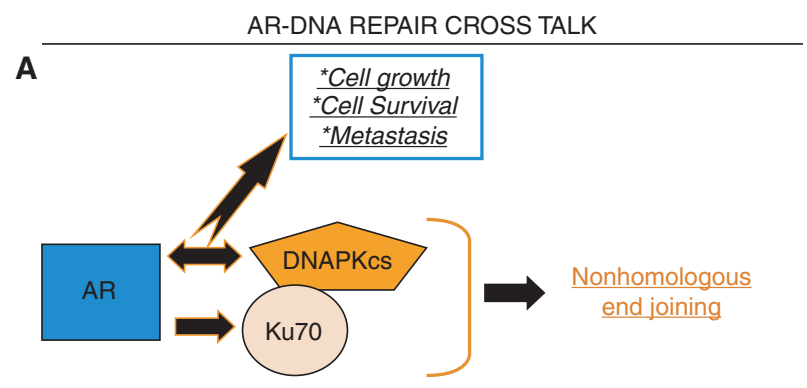

B

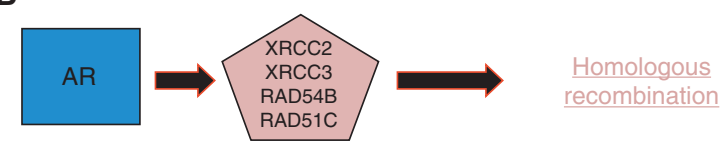

C

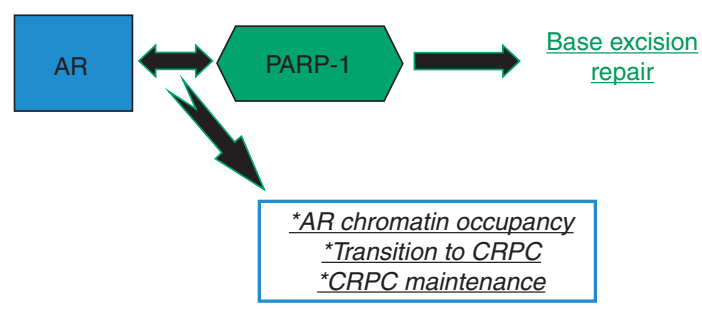

Figure 2. Androgen receptor (AR)-DNA repair cross talk. (A) The AR regulates the expression of key nonhomologous end joining (NHEJ) factors, namely, DNA-dependent kinase catalytic subunit (DNAPKcs) (mRNA, protein, and kinase function) and Ku70 (protein). As such, AR is a key determinant of NHEJ capacity. Furthermore, AR and DNAPKcs show a feed-forward loop in which AR drives the expression of DNAPKcs, and DNAPKcs serves as a coactivator of AR transcriptional activity. This feed-forward loop drives tumor cell growth and survival, as well as the development of metastases. Importantly, DNAPKcs is the most frequently deregulated kinase in tumors that go on to metastasize. $(B)$ AR drives the expression of mRNA encoding several homologous recombination (HR) factors, including XRCC2, XRCC3, RAD54B, and RAD51C. (C) AR and poly(ADP-ribose) polymerase-1 (PARP-1) exist in a feed-forward loop, wherein AR drives the mRNA expression of PARP-1, and PARP-1 enzymatic activity is required for maximal AR transcriptional function. Pharmacological targeting of PARP-1 results in diminished AR occupancy on chromatin, prolongs the transition to castration-resistant prostate cancer (CRPC), and diminishes CRPC growth.

platforms analyzing 333 primary PCa specimens. These data indicate that there is a significant amount of heterogeneity in PCa. However, the TCGA effort also uncovered that $19 \%$ of localized prostate tumors have inactivation of DNA repair genes, the majority of which were found in the HR pathway. These included $1 \%$ of tumors with mutation in BRCA1,3\% with aberrant BRCA2 (mutation and homozygous deletion), and $3 \%$ with deletion of RAD51C (mostly heterozygous deletion). Additionally, key kinases involved in DNA repair were found to be altered in primary PCa: $4 \%$ mutation rate of ATM and $2 \%$ aberrant CDK12 (mutation and heterozygous deletion); $6 \%$ of this cohort harbored alterations in FANCD2, a key player in the Fanconi anemia pathway (Cancer Genome Atlas Research 2015). These data indicate that defects in DNA repair genes are much more frequent than previously appreciated or reported (1.3\%, Taylor et al. 2010), although this study was not designed to comprehensively assess DNA repair gene aberrations. Furthermore, a multi-omics study of localized intermediate 
M.J. Schiewer and K.E. Knudsen

risk PCa further showed DNA repair defects are much less frequent in early stage disease. In this study, $1.75 \%$ of the tumors harbored deleterious mutations in ATM. Although no single gene was altered in $>10 \%$ of cases (DNA repair-related or otherwise) in this cohort, likely because of the overall low mutation frequency of primary $\mathrm{PCa}$, ATM alteration was nonetheless the only gene that showed prognostic value (Fraser et al. 2017b). Although these studies were informative for primary $\mathrm{PCa}$, this disease stage is typically not lethal. Therefore, it is imperative to understand the landscape of DNA repair genes in CRPC.

\section{DNA Repair Defects in Advanced PCa}

One of the first studies to compare the mutational burden in CRPC and compare to primary PCa found many more genetic abnormalities in DNA repair factors (ERCC5, BRCA2, ATM, PRKDC, RAD50, XRCC4, ERCC4, and ERCC2) in CRPC (23/50) than in treatment-naïve, highgrade localized tumors $(3 / 11)$. These data were the first to suggest that there is an enrichment of DDR pathway aberrations during PCa progression (Grasso et al. 2012). The International Stand Up to Cancer (SU2C) PCa study recently published exome sequencing data from 150 metastatic CRPC tumors, showing a surprising $8 \%$ of mCRPC harbor germline DDR pathway aberrations, and $23 \%$ of these tumors have somatic DNA repair pathway alterations. $B R C A 2$ was the most frequently altered DDR gene $(12.7 \%$ of the cases studied), and $\sim 90 \%$ of these BRCA2 defective tumors showed biallelic loss (loss of heterozygosity $[\mathrm{LOH}]$ or a mutation on the second allele). Of the overall cohort, 5.3\% harbored germline BRCA2 mutations, a frequency higher than primary disease. Additionally, four tumors in this cohort were found to have a hypermutated genome, and three of these harbored defects in $M L H 1$ or $M S H 2$. Other genes that were altered in these mCRPC samples include $A T M$, BRCA1, CDK12, FANCA, RAD51B, and RAD51C, with $A T M$ being the second most altered gene (6/150 somatic, 2/150 germline). Aberrations in ATM, BRCA1, or BRCA2 may render tumors HR-defective and potentially more sensi- tive to PARP inhibitors (PARPi) and platinumbased chemotherapy. If this hypothesis is correct, $\sim 20 \%$ of mCRPC patients would potentially benefit from these therapeutic strategies, which also has implications for the large number of patients that must be screened to get to these 20\% (Robinson et al. 2015b).

In a more recent study, a large cohort of men with mCRPC $(n=692)$ with no family history at time of diagnosis was used to study germline mutational status of 20 DNA repair genes associated with familial cancer-predisposition syndromes. Remarkably, $11.8 \%$ of the tumors in this cohort harbored mutations (presumed deleterious) in 16 of these genes, with alterations in $B R C A 2$ being most frequent (5.3\%). In contrast, only $4.6 \%$ of the tumors in a cohort of 499 men with nondisseminated PCa harbored mutations in these 20 DNA repair genes (Pritchard et al. 2016). In sum, PCa features an enrichment of both germline and somatic alterations in DNA repair genes, which provides the impetus of clinically evaluating the targeting of DNA repair in PCa management

One such evaluation of targeting DNA repair is a recently published phase 2 clinical trial testing the efficacy of the PARPi olaparib in 50 mCRPC patients. In addition to having failed ADT, these patients had also progressed on docetaxel (100\%), enzalutamide or abiraterone (98\%), and cabizitaxel (58\%) (Mateo et al. 2015). Of the cohort that could be analyzed, $33 \%$ had a response to olaparib, with 12 of 16 of these patients being on treatment longer than 6 months. Tumors from these patients underwent next-generation sequencing, and of the responders, $14 / 16$ were considered to have potential defects in DNA repair, including aberrations in several DNA repair factors. Biomarker positivity was assigned in some cases of single copy hits. Seven tumors of the total cohort $(\sim 14 \%)$ were found to be BRCA2-null (four biallelic somatic loss, three germline mutation with $\mathrm{LOH}$ ), and patients harboring loss of BRCA2 all had durable responses of at least 6 months. Three of 49 tumors had germline ATM mutations, although three other tumors harbored homozygous deletion of FANCA, and in both cases two of three patients with ATM or FANCA altered 
tumors responded to PARPi. Two tumors were homozygously deleted for CHEK2, and one of the patients with aberrant CHEK2 had a response to PARPi. Finally, one tumor harbored PALB2 aberration, and this patient was PARPiresponsive (Mateo et al. 2015). These data indicate that there is enrichment for PARPi efficacy in heavily pretreated $\mathrm{MCRPC}$ patients with DNA repair defects, although the association is not perfect. The success of this trial lead to the U.S. Food and Drug Administration giving "breakthrough therapy designation" to olaparib for treatment of mCRPC patients with tumors harboring ATM, BRCA1, or BRCA2 alterations in early 2016.

As described above, DNA repair defects are overall much more common in PCa than previously appreciated, and these defects are enriched in advanced disease. To further illustrate this point, the publicly available Memorial Sloan Kettering Cancer Center cBioportal (Cerami et al. 2012; Gao et al. 2013) was queried against all available PCa data sets for DDR gene mutation and copy number alterations. As seen in Figure 3 (left), the frequency of genetic defects (copy number alteration and mutation) in DNA repair genes range is variable depending on the DNA repair pathway queried. Using cBioportal clinical data, if primary $\mathrm{PCa}$ (the results shown here are in whole or part based on data generated by the TCGA Research Network; see cancergenome.nih.gov/) (Cancer Genome Atlas Research 2015) is compared with metastatic PCa (SU2C data set) (Fig. 3) (Robinson et al. 2015b), the relative frequency of alterations in BER is slightly elevated in advanced disease compared with primary (18\% and $13 \%$, respectively). In contrast, there is no enrichment of NER defects in metastatic (21\%) versus primary PCa (20\%). Similarly, the frequency of alterations in MMR is very similar in localized (13\%) and disseminated (14\%) PCa. However, the HR pathway is the most frequently aberrant DDR system in PCa and is significantly enriched in advanced disease ( $22 \%$ vs. $31 \%)$, which indicate this tumor type may be especially amenable to use of platinum agents and/or PARPi. Finally, alterations of the NHEJ pathway are also enriched in metastatic PCa (18\%) when compared with primary PCa
(10\%). The contrast between primary PCa and advanced disease is even more striking when only percentage of cohort harboring mutations is considered (Fig. 3, right). Together, the published and publicly available data indicate that there are frequent alterations in DDR pathways, HR being the most commonly defective mechanism, and there tends to be an increase in DDR aberrations on disease progression.

\section{CLINICAL TRIALS TARGETING DNA REPAIR FACTORS}

As described above, deregulation of DNA repair is a frequent event in $\mathrm{PCa}$, and there is an important interplay of DDR and AR, a key driver of PCa. As shown in Table 1, there are a large number of clinical trials using targeted therapies against key DNA repair factors in the context of PCa. These will be outlined below:

\section{Kinases}

Loss of BRCA1/2 function leads to replicative stress (Fridlich et al. 2015) and activation of cell cycle checkpoints, which includes $\mathrm{CHK} 1 / 2$ activation (Zannini et al. 2014). To exploit this, a phase 2 trial of a $\mathrm{CHK} 1 / 2$ inhibitor in multiple tumors types that harbor BRCA1/2 defects, including metastatic CRPC, has been designed (NCT02203513). There is a significant body of data that shows that DNAPKcs has multiple functions in malignancy (Goodwin and Knudsen 2014), that there is an AR-DNAPKcs feed-forward loop (Goodwin et al. 2013), and that DNAPKcs is both causative of metastasis and of prognostic value in PCa (Goodwin et al. 2015). Based on these data, a clinical trial has been designed combining CC-115 (a dual DNAPKcs/ TOR kinase inhibitor) and enzalutamide in metastatic CRPC (NCT02833883).

\section{PARP Inhibition}

Although there have been trials showing promise of PARPi in CRPC, it is likely we are only beginning to scratch the surface of the therapeutic potential of DNA repair pathways in $\mathrm{PCa}$ management. In fact, DDR defects may provide 
M.J. Schiewer and K.E. Knudsen

COPY NUMBER AND MUTATION

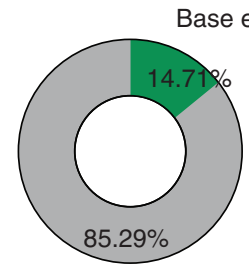

Primary PCa (TCGA)

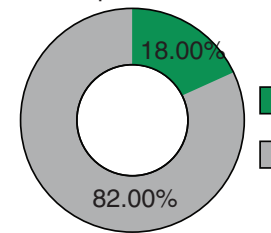

Metastatic PCa (SU2C)
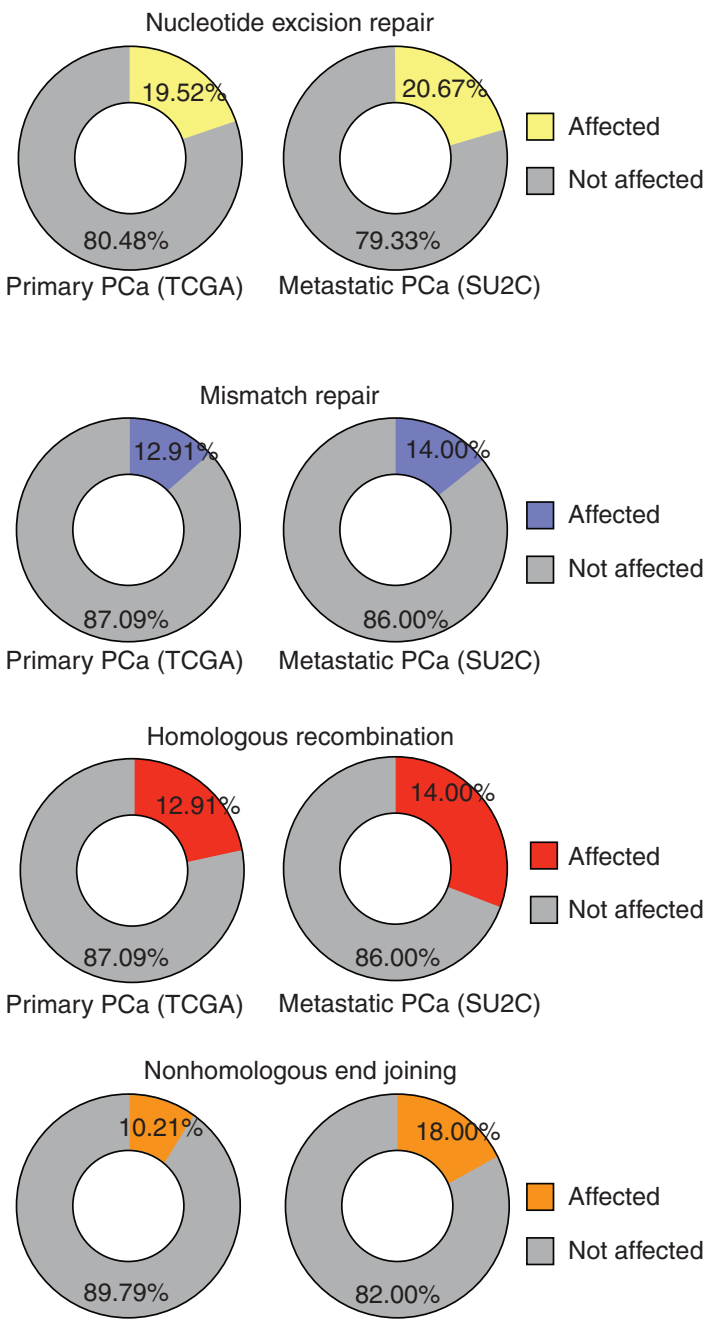

ogous end joining

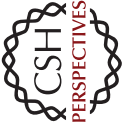

Primary PCa (TCGA) Metastatic PCa (SU2C)

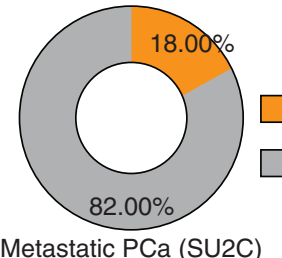

Affected

Not affected
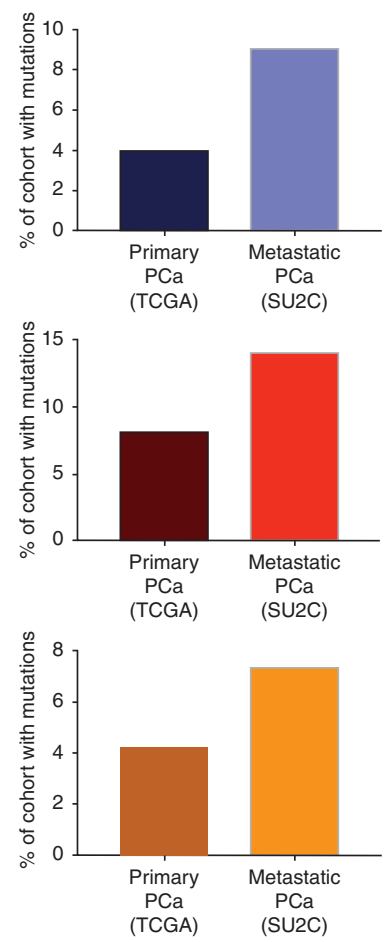

Figure 3. DNA damage response and repair (DDR) defects increase as a function of disease progression. The Memorial Sloan Kettering cBioportal database was queried for genes in each of the main DNA repair pathways using the Cancer Genome Atlas (TCGA) data set for primary prostatic adenocarcinoma (PCa) and the International Stand Up to Cancer (SU2C) data set for advanced, metastatic disease. As shown, the prevalence of mutations and/or copy number alterations is more frequent in advanced disease (left panels). This increase is more striking when only mutations are considered (right panels). DNA repair alterations are more frequent in advanced PCa. 


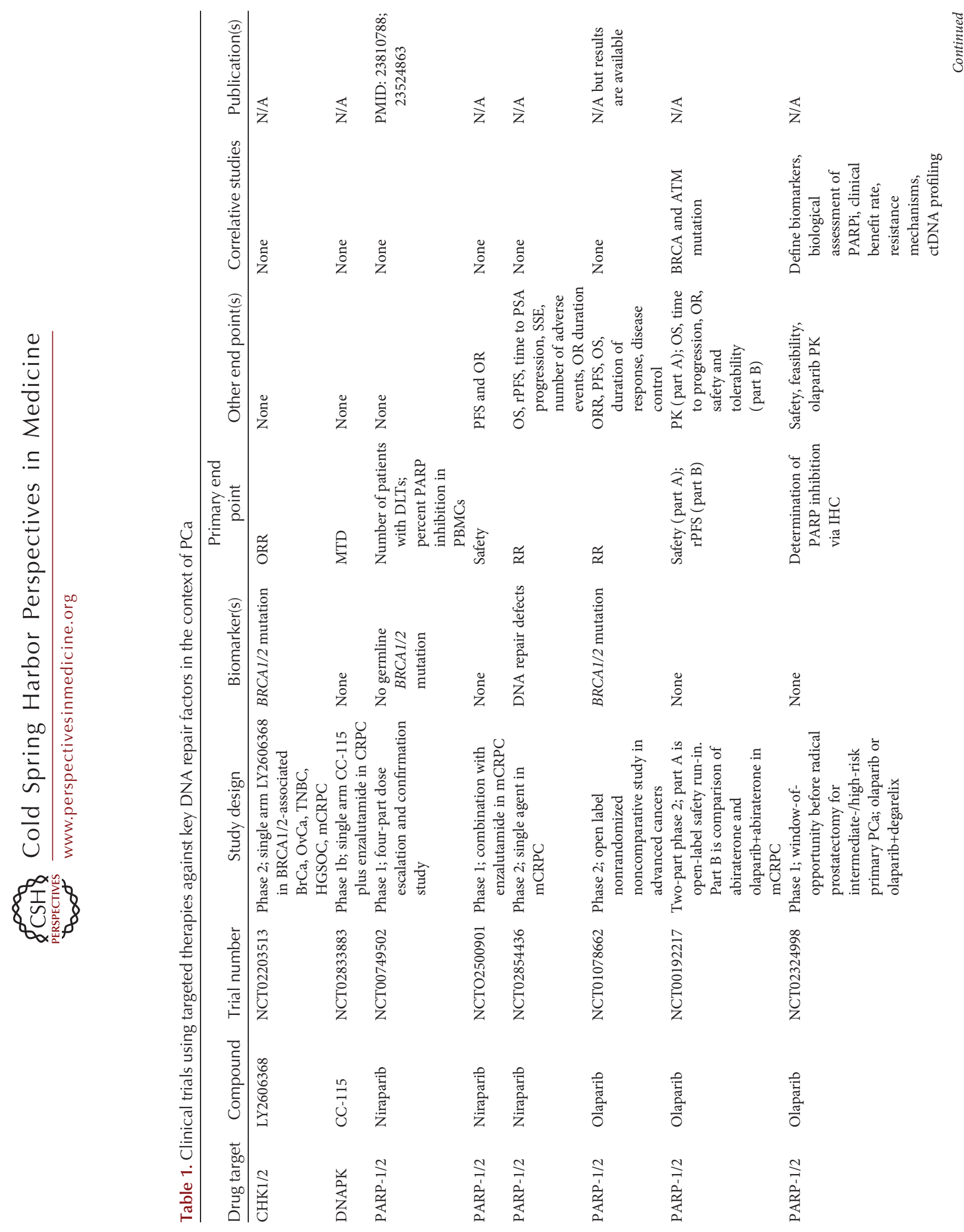



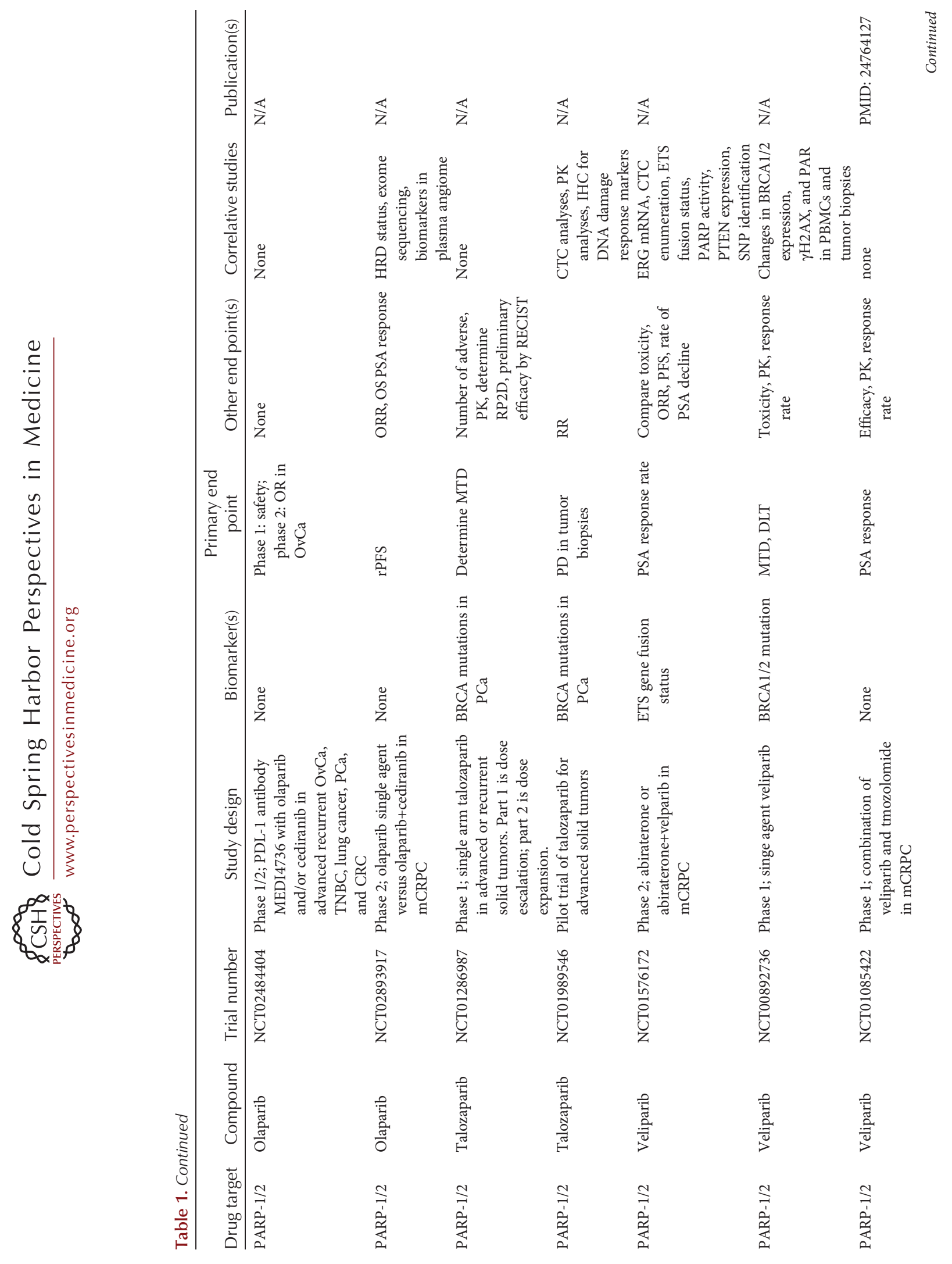

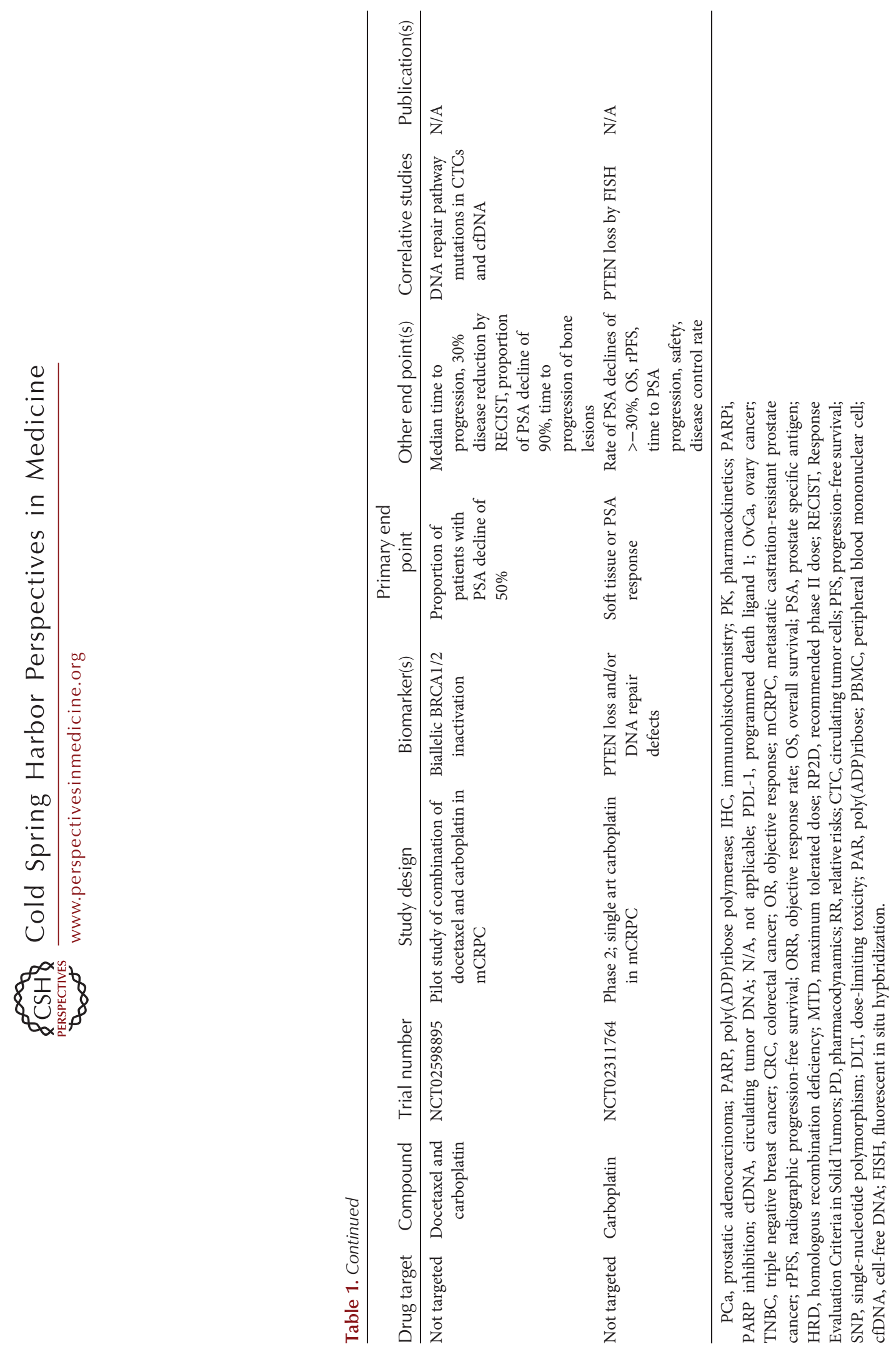
the impetus to revisit platinum-based chemotherapeutic regimens in patient populations selected for aberrant DNA repair. Given that targeting PARP-1/2 in the context of HR defects elicits synthetic lethality (Lord et al. 2015), a number of trials have been designed to test PARPi as a single agent in advanced PCa with DDR defects (NCT02854436) and BRCA1/2 mutation (NCT01078662, NCT01286987, NCT01989546, NCT00892736). Despite the enrichment of PARPi responses being linked to HR defects, preclinical data suggest that PARP-1 regulates the function of AR, and that PARPi and ADT delay CRPC progression and cooperate in de novo CRPC model systems that do not harbor HR defects (Schiewer et al. 2012). Several trials have been designed that combine PARPi and second- or third-line AR-directed therapies (NCT02500901, NCT 01972217, NCT02324998, NCT01576172). Furthermore, a number of clinical trials in multiple tumor types that did not select for BRCA mutations demonstrate that patients with BRCA-intact tumors show objective responses (Gelmon et al. 2011; Sandhu et al. 2013). As such, one study has been designed to test the efficacy of PARPi without preselection for BRCA mutations (NCT00749502). Although PARPi has shown promise as a single agent, PARPi alone may not be curative. Several trials using combinatorial strategies have been developed combining PARPi with vascular endothelial growth factor (VEGF) inhibition (NCT02893917), VEGF inhibition and/or immunotherapy (NCT 02484404), or tomozolomide (NCT01085422). Finally, DNA repair defects in triple negative breast cancer (TNBC) enrich for responses to platinum agents (Telli et al. 2016), and there is evidence that there is overlap in sensitivity of platinum and PARPi. As such, trials of platinum alone (NCT02311764) and in combination with taxanes (NCT02598895) have been designed in advanced prostate cancers harboring DNA repair aberrations.

\section{CONCLUDING REMARKS}

In summary, there is significant evidence that DNA repair pathways are relevant in PCa. This is based on the frequency with which these pathways are deregulated on prostate oncogenesis, as well as the complex reciprocal regulation of DDR components and the AR. The field of DNA repair in PCa is fast becoming rediscovered as critical to understanding PCa biology and discovering new means to thwart this malignancy.

Although the observations described above indicate that significant inroads have been made in DNA repair research in PCa, several key questions remain. First, do alterations in DNA repair factors alter AR function and subsequent efficacy of ADT? In most large published data sets that show the high frequency of DDR alterations in $\mathrm{PCa}$, the impact these defects have on the mainstay of treatment of disseminated disease has yet to be determined. Second, how can the DNA repair deficiencies found in PCa be exploited therapeutically? It appears that HR defects will enrich in those tumors that respond to PARPi, but not all PARPi responders have readily apparent DDR aberrations, nor do all tumors harboring DDR mutations/deletions respond to PARPi. It is likely that PARPi will soon become part of the standard of care of CRPC; however the best use of PARPi remains to be elucidated. Similarly, use of inhibitors of other DNA repair proteins needs to be properly vetted in PCa. Third, are DNA repair defects playing a role in innate or acquired resistance to ARdirected therapeutic strategies? Given that DNA-PKcs is the most frequently up-regulated kinase in CRPC, it is potentially involved in $\mathrm{ADT}$ resistance. It will be imperative to determine the relative contributions of DNA repair defects to response to such a commonly used therapy and attempt to stratify patients accordingly. Fourth, can DDR aberrations be developed as biomarkers to predict tumor progression? Functional assessment of the biological impact of the DNA repair gene defects is of high importance. Fifth, what is the clinical relevance of the DDR-AR interplay? We are only beginning to understand how AR and DNA repair factors regulate each other. Future clinical trial design would benefit from the prioritization of confirming these functional interactions and determine the best means to use this knowledge therapeutically. Sixth, is it time for selected 
trials of platinum agents in PCa? In triple-negative breast cancer, the connection between PARPi response and BRCA1/2 status is more closely linked than in PCa (Anders et al. 2010). However, platinums tend to be effective in patients with a spectrum of DDR defects that may be less severe than BRCA1/2 loss of function (Birkbak et al. 2012). Seventh, is it possible to define DDR defects outside of SNPs, mutations, and copy number alterations? Because not all tumors that respond to agents that target homologous recombination defects harbor identifiable mutations in the genes that we currently understand are required for this DNA repair pathway, efforts have been made to identify tumors with homologous repair deficiencies by searching for patterns of chromosomal abnormalities that might be caused by tumor growth in the absence of this repair pathway (Birkbak et al. 2012). These signatures have been combined into the homologous recombination deficiency (HRD) assay, currently under evaluation in a number of settings (Telli et al. 2016) and in clinical trials (including NCT01982448 in breast cancer and NCT02893917 in prostate cancer). Such assays of "genomic scars" may be an alternative method of identifying tumors that may respond to platinum agents and/or PARPi. Finally, what is the absolute frequency of DNA repair defects in $\mathrm{PCa}$, and are these alterations driving tumorigenesis and disease progression? Given the wide-ranging reports of how frequently DDR genes are altered in PCa (from $<5 \%$ to $>70 \%$ ), it is necessary to better define the frequency with which key DDR players are deregulated, whether these alterations are driving malignant phenotypes, and how best to target these tumors. Future studies should be undertaken to increase our mechanistic understanding of DDR defects in PCa and how the DDR functions in general in $\mathrm{PCa}$, determine the biological and clinical importance of DNA repair alterations, and attempt to leverage this knowledge for better PCa diagnostic, prognostic, and therapeutic management.

\section{REFERENCES}

Abbotts R, Wilson DM III. 2016. Coordination of DNA single strand break repair. Free Radic Biol Med 107: 228-244.
Al-Ubaidi FL, Schultz N, Loseva O, Egevad L, Granfors T, Helleday T. 2013. Castration therapy results in decreased Ku70 levels in prostate cancer. Clin Cancer Res 19: 15471556.

Anders CK, Winer EP, Ford JM, Dent R, Silver DP, Sledge GW, Carey LA. 2010. Poly(ADP-ribose) polymerase inhibition: "Targeted" therapy for triple-negative breast cancer. Clin Cancer Res 16: 4702-4710.

Angele S, Falconer A, Edwards SM, Dork T, Bremer M, Moullan N, Chapot B, Muir K, Houlston R, Norman AR, et al. 2004. ATM polymorphisms as risk factors for prostate cancer development. Br J Cancer 91: 783-787.

Baca SC, Prandi D, Lawrence MS, Mosquera JM, Romanel A, Drier Y, Park K, Kitabayashi N, MacDonald TY, Ghandi M, et al. 2013. Punctuated evolution of prostate cancer genomes. Cell 153: 666-677.

Barbieri CE, Baca SC, Lawrence MS, Demichelis F, Blattner M, Theurillat JP, White TA, Stojanov P, Van Allen E Stransky N, et al. 2012. Exome sequencing identifies recurrent SPOP, FOXA1 and MED12 mutations in prostate cancer. Nat Genet 44: 685-689.

Bartek J, Lukas J, Bartkova J. 2007. DNA damage response as an anti-cancer barrier: Damage threshold and the concept of 'conditional haploinsufficiency'. Cell Cycle 6: 23442347.

Bartkova J, Horejsi Z, Koed K, Kramer A, Tort F, Zieger K, Guldberg P, Sehested M, Nesland JM, Lukas C, et al. 2005. DNA damage response as a candidate anti-cancer barrier in early human tumorigenesis. Nature 434: 864-870.

Beltran H, Wyatt AW, Chedgy E, Donoghue A, Annala M, Warner E, Beja K, Sigouros M, Mo F, Fazli L, et al. 2017. Impact of therapy on genomics and transcriptomics in high-risk prostate cancer treated with neoadjuvant docetaxel and androgen deprivation therapy. Clin Cancer Res 23: 6802-6811.

Beltran H, Yelensky R, Frampton GM, Park K, Downing SR, MacDonald TY, Jarosz M, Lipson D, Tagawa ST, Nanus DM, et al. 2013. Targeted next-generation sequencing of advanced prostate cancer identifies potential therapeutic targets and disease heterogeneity. Eur Urol 63: 920-926.

Berger MF, Lawrence MS, Demichelis F, Drier Y, Cibulskis K, Sivachenko AY, Sboner A, Esgueva R, Pflueger D, Sougnez C, et al. 2011. The genomic complexity of primary human prostate cancer. Nature 470: 214-220.

Bhattacharjee S, Nandi S. 2016. Choices have consequences: The nexus between DNA repair pathways and genomic instability in cancer. Clin Transl Med 5: 45.

Birkbak NJ, Wang ZC, Kim JY, Eklund AC, Li Q, Tian R, Bowman-Colin C, Li Y, Greene-Colozzi A, Iglehart JD, et al. 2012. Telomeric allelic imbalance indicates defective DNA repair and sensitivity to DNA-damaging agents. Cancer Discov 2: 366-375.

Bolla M, Gonzalez D, Warde P, Dubois JB, Mirimanoff RO, Storme G, Bernier J, Kuten A, Sternberg C, Gil T, et al 1997. Improved survival in patients with locally advanced prostate cancer treated with radiotherapy and goserelin. N Engl J Med 337: 295-300.

Bolla M, Verry C, Long JA. 2013. High-risk prostate cancer: Combination of high-dose, high-precision radiotherapy and androgen deprivation therapy. Curr Opin Urol 23: 349-354. 
M.J. Schiewer and K.E. Knudsen

Brenner JC, Ateeq B, Li Y, Yocum AK, Cao Q, Asangani IA, Patel S, Wang X, Liang H, Yu J, et al. 2011. Mechanistic rationale for inhibition of poly(ADP-ribose) polymerase in ETS gene fusion-positive prostate cancer. Cancer Cell 19: 664-678.

Brown JS, O'Carrigan B, Jackson SP, Yap TA. 2017. Targeting DNA repair in cancer: Beyond PARP inhibitors. Cancer Discov 7: 20-37.

Cancer Genome Atlas Research Network. 2015. The molecular taxonomy of primary prostate cancer. Cell 163: 1011-1025.

Castro E, Goh C, Leongamornlert D, Saunders E, Tymrakiewicz M, Dadaev T, Govindasami K, Guy M, Ellis S, Frost D, et al. 2015. Effect of BRCA mutations on metastatic relapse and cause-specific survival after radical treatment for localised prostate cancer. Eur Urol 68: 186-193.

Castro E, Goh C, Olmos D, Saunders E, Leongamornlert D, Tymrakiewicz M, Mahmud N, Dadaev T, Govindasami K, Guy M, et al. 2013. Germline BRCA mutations are associated with higher risk of nodal involvement, distant metastasis, and poor survival outcomes in prostate cancer. J Clin Oncol 31: 1748-1757.

Ceccaldi R, Rondinelli B, D’Andrea AD. 2015. Repair pathway choices and consequences at the double-strand break. Trends Cell Biol 26: 52-64.

Cerami E, Gao J, Dogrusoz U, Gross BE, Sumer SO, Aksoy BA, Jacobsen A, Byrne CJ, Heuer ML, Larsson E, et al. 2012. The cBio cancer genomics portal: An open platform for exploring multidimensional cancer genomics data. Cancer Discov 2: 401-404.

Chang CH, Chiu CF, Wu HC, Tseng HC, Wang CH, Lin CC, Tsai CW, Liang SY, Wang CL, Bau DT. 2008. Significant association of XRCC4 single nucleotide polymorphisms with prostate cancer susceptibility in Taiwanese males. Mol Med Rep 1: 525-530.

Colotta F, Allavena P, Sica A, Garlanda C, Mantovani A. 2009. Cancer-related inflammation, the seventh hallmark of cancer: Links to genetic instability. Carcinogenesis 30: 1073-1081.

Cotter K, Konety B, Ordonez MA. 2016. Contemporary management of prostate cancer. F1000Res 5: 179.

Coutinho I, Day TK, Tilley WD, Selth LA. 2016. Androgen receptor signaling in castration-resistant prostate cancer: A lesson in persistence. Endocr Relat Cancer 23: T179T197.

Cybulski C, Wokolorczyk D, Kluzniak W, Jakubowska A, Gorski B, Gronwald J, Huzarski T, Kashyap A, Byrski T, Debniak T, et al. 2013. An inherited NBN mutation is associated with poor prognosis prostate cancer. $\mathrm{Br} \mathrm{J} \mathrm{Can-}$ cer 108: 461-468.

Dominguez-Valentin $\mathrm{M}$, Joost $\mathrm{P}$, Therkildsen $\mathrm{C}$, Jonsson $\mathrm{M}$, Rambech E, Nilbert M. 2016. Frequent mismatch-repair defects link prostate cancer to Lynch syndrome. BMC Urol 16: 15.

Ermolaeva MA, Dakhovnik A, Schumacher B. 2015. Quality control mechanisms in cellular and systemic DNA damage responses. Ageing Res Rev 23: 3-11.

Ferraldeschi R, Welti J, Luo J, Attard G, de Bono JS. 2015. Targeting the androgen receptor pathway in castrationresistant prostate cancer: Progresses and prospects. Oncogene 34: 1745-1757.
Fraser M, Sabelnykova VY, Yamaguchi TN, Heisler LE, Livingstone J, Huang V, Shiah YJ, Yousif F, Lin X, Masella AP, et al. 2017a. Genomic hallmarks of localized, nonindolent prostate cancer. Nature 541: 359-364.

Fraser M, Sabelnykova VY, Yamaguchi TN, Heisler LE, Livingstone J, Huang V, Shiah YJ, Yousif F, Lin X, Masella AP, et al. 2017b. Genomic hallmarks of localized, nonindolent prostate cancer. Nature 541: 359-364.

Fridlich R, Annamalai D, Roy R, Bernheim G, Powell SN. 2015. BRCA1 and BRCA2 protect against oxidative DNA damage converted into double-strand breaks during DNA replication. DNA Repair (Amst) 30: 11-20.

Gallagher DJ, Gaudet MM, Pal P, Kirchhoff T, Balistreri L, Vora K, Bhatia J, Stadler Z, Fine SW, Reuter V, et al. 2010. Germline BRCA mutations denote a clinicopathologic subset of prostate cancer. Clin Cancer Res 16: 2115-2121.

Gao J, Aksoy BA, Dogrusoz U, Dresdner G, Gross B, Sumer SO, Sun Y, Jacobsen A, Sinha R, Larsson E, et al. 2013. Integrative analysis of complex cancer genomics and clinical profiles using the cBioPortal. Sci Signal 6: pl1.

Gasi Tandefelt D, Boormans J, Hermans K, Trapman J. 2014. ETS fusion genes in prostate cancer. Endocr Relat Cancer 21: R143-R152.

Gelmon KA, Tischkowitz M, Mackay H, Swenerton K, Robidoux A, Tonkin K, Hirte H, Huntsman D, Clemons M, Gilks B, et al. 2011. Olaparib in patients with recurrent high-grade serous or poorly differentiated ovarian carcinoma or triple-negative breast cancer: A phase 2, multicentre, open-label, non-randomised study. Lancet Oncol 12: $852-861$.

Goodwin JF, Knudsen KE. 2014. Beyond DNA repair: DNAPK function in cancer. Cancer Discov 4: 1126-1139.

Goodwin JF, Kothari V, Drake JM, Zhao S, Dylgjeri E, Dean JL, Schiewer MJ, McNair C, Jones JK, Aytes A, et al. 2015. DNA-PKcs-mediated transcriptional regulation drives prostate cancer progression and metastasis. Cancer Cell 28: 97-113.

Goodwin JF, Schiewer MJ, Dean JL, Schrecengost RS, de Leeuw R, Han S, Ma T, Den RB, Dicker AP, Feng FY, et al. 2013. A hormone-DNA repair circuit governs the response to genotoxic insult. Cancer Discov 3: 1254-1271.

Graham L, Schweizer MT. 2016. Targeting persistent androgen receptor signaling in castration-resistant prostate cancer. Med Oncol 33: 44.

Grasso CS, Wu YM, Robinson DR, Cao X, Dhanasekaran SM, Khan AP, Quist MJ, Jing X, Lonigro RJ, Brenner JC, et al. 2012. The mutational landscape of lethal castrationresistant prostate cancer. Nature 487: 239-243.

Grindedal EM, Moller P, Eeles R, Stormorken AT, BowitzLothe IM, Landro SM, Clark N, Kvale R, Shanley S, Maehle L. 2009. Germ-line mutations in mismatch repair genes associated with prostate cancer. Cancer Epidemiol Biomarkers Prev 18: 2460-2467.

Haffner MC, Aryee MJ, Toubaji A, Esopi DM, Albadine R, Gurel B, Isaacs WB, Bova GS, Liu W, Xu J, et al. 2010. Androgen-induced TOP2B-mediated double-strand breaks and prostate cancer gene rearrangements. $\mathrm{Nat} \mathrm{Ge-}$ net 42: 668-675.

Hanahan D, Weinberg RA. 2011. Hallmarks of cancer: The next generation. Cell 144: 646-674. 
Henriquez-Hernandez LA, Valenciano A, Foro-Arnalot P, Alvarez-Cubero MJ, Cozar JM, Suarez-Novo JF, CastellsEsteve M, Fernandez-Gonzalo P, De-Paula-Carranza B, Ferrer M, et al. 2016. Association between single-nucleotide polymorphisms in DNA double-strand break repair genes and prostate cancer aggressiveness in the Spanish population. Prostate Cancer Prostatic Dis 19: 28-34.

Hustedt N, Durocher D. 2016. The control of DNA repair by the cell cycle. Nat Cell Biol 19: 1-9.

Imielinski M, Rubin MA. 2017. Prostate cancer: Clinical hallmarks in whole cancer genomes. Nat Rev Clin Oncol 14: $265-266$

Jaamaa S, Laiho M. 2012. Maintenance of genomic integrity after DNA double strand breaks in the human prostate and seminal vesicle epithelium: The best and the worst. Mol Oncol 6: 473-483

Jeggo PA, Pearl LH, Carr AM. 2016. DNA repair, genome stability and cancer: a historical perspective. Nat Rev Cancer 16: 35-42.

Ju BG, Lunyak VV, Perissi V, Garcia-Bassets I, Rose DW, Glass CK, Rosenfeld MG. 2006. A topoisomerase II $\beta$-mediated dsDNA break required for regulated transcription. Science 312: 1798-1802.

Kote-Jarai Z, Jugurnauth S, Mulholland S, Leongamornlert DA, Guy M, Edwards S, Tymrakiewitcz M, O’Brien L, Hall A, Wilkinson R, et al. 2009. A recurrent truncating germline mutation in the BRIP1/FANCJ gene and susceptibility to prostate cancer. Br J Cancer 100: 426-430.

Kumar A, Coleman I, Morrissey C, Zhang X, True LD, Gulati R, Etzioni R, Bolouri H, Montgomery B, White T, et al. 2016. Substantial interindividual and limited intraindividual genomic diversity among tumors from men with metastatic prostate cancer. Nat Med 22: 369-378.

Kumar A, Shendure J, Nelson PS. 2011a. Genome interrupted: Sequencing of prostate cancer reveals the importance of chromosomal rearrangements. Genome Med 3: 23.

Kumar A, White TA, MacKenzie AP, Clegg N, Lee C, Dumpit RF, Coleman I, Ng SB, Salipante SJ, Rieder MJ, et al. 2011b. Exome sequencing identifies a spectrum of mutation frequencies in advanced and lethal prostate cancers. Proc Natl Acad Sci 108: 17087-17092.

Lavery HJ, Cooperberg MR. 2017. Clinically localized prostate cancer in 2017: A review of comparative effectiveness. Urol Oncol 35: 40-41.

Leongamornlert D, Mahmud N, Tymrakiewicz M, Saunders E, Dadaev T, Castro E, Goh C, Govindasami K, Guy M, O'Brien L, et al. 2012. Germline BRCA1 mutations increase prostate cancer risk. Br J Cancer 106: 1697-1701.

Leongamornlert D, Saunders E, Dadaev T, Tymrakiewicz M, Goh C, Jugurnauth-Little S, Kozarewa I, Fenwick K, Assiotis I, Barrowdale D, et al. 2014. Frequent germline deleterious mutations in DNA repair genes in familial prostate cancer cases are associated with advanced disease. Br J Cancer 110: 1663-1672.

Lin C, Yang L, Tanasa B, Hutt K, Ju BG, Ohgi K, Zhang J, Rose DW, Fu XD, Glass CK, et al. 2009. Nuclear receptorinduced chromosomal proximity and DNA breaks underlie specific translocations in cancer. Cell 139: 10691083.

Lord CJ, Tutt AN, Ashworth A. 2015. Synthetic lethality and cancer therapy: Lessons learned from the development of PARP inhibitors. Annu Rev Med 66: 455-470.
Mandal RK, Singh V, Kapoor R, Mittal RD. 2011. Do polymorphisms in XRCC4 influence prostate cancer susceptibility in North Indian population? Biomarkers 16: 236 242.

Mani RS, Tomlins SA, Callahan K, Ghosh A, Nyati MK, Varambally S, Palanisamy N, Chinnaiyan AM. 2009. Induced chromosomal proximity and gene fusions in prostate cancer. Science 326: 1230.

Mateo J, Carreira S, Sandhu S, Miranda S, Mossop H, PerezLopez R, Nava Rodrigues D, Robinson D, Omlin A, Tunariu N, et al. 2015. DNA-repair defects and olaparib in metastatic prostate cancer. N Engl J Med 373: 1697-1708.

McCulloch SD, Kunkel TA. 2008. The fidelity of DNA synthesis by eukaryotic replicative and translesion synthesis polymerases. Cell Res 18: 148-161.

Mirecka A, Paszkowska-Szczur K, Scott RJ, Gorski B, van de Wetering T, Wokolorczyk D, Gromowski T, Serrano-Fernandez P, Cybulski C, Kashyap A, et al. 2014. Common variants of xeroderma pigmentosum genes and prostate cancer risk. Gene 546: 156-161.

Mittal RD, Mandal RK. 2012. Genetic variation in nucleotide excision repair pathway genes influence prostate and bladder cancer susceptibility in North Indian population. Indian J Hum Genet 18: 47-55.

Mittal RD, Mandal RK, Gangwar R. 2012. Base excision repair pathway genes polymorphism in prostate and bladder cancer risk in North Indian population. Mech Ageing Dev 133: 127-132.

Polkinghorn WR, Parker JS, Lee MX, Kass EM, Spratt DE, Iaquinta PJ, Arora VK, Yen WF, Cai L, Zheng D, et al. 2013. Androgen receptor signaling regulates DNA repair in prostate cancers. Cancer Discov 3: 1245-1253.

Pritchard CC, Mateo J, Walsh MF, De Sarkar N, Abida W, Beltran H, Garofalo A, Gulati R, Carreira S, Eeles R, et al. 2016. Inherited DNA-repair gene mutations in men with metastatic prostate cancer. N Engl J Med 375: 443-453.

Pritchard CC, Morrissey C, Kumar A, Zhang X, Smith C, Coleman I, Salipante SJ, Milbank J, Yu M, Grady WM, et al. 2014. Complex MSH2 and MSH6 mutations in hypermutated microsatellite unstable advanced prostate cancer. Nat Commun 5: 4988.

Rickman DS, Soong TD, Moss B, Mosquera JM, Dlabal J, Terry S, MacDonald TY, Tripodi J, Bunting K, Najfeld V, et al. 2012. Oncogene-mediated alterations in chromatin conformation. Proc Natl Acad Sci 109: 9083-9088.

Ritch CR, Cookson MS. 2016. Advances in the management of castration resistant prostate cancer. BMJ 355: i4405

Robinson D, Van Allen EM, Wu YM, Schultz N, Lonigro RJ, Mosquera JM, Montgomery B, Taplin ME, Pritchard CC, Attard G, et al. 2015a. Integrative clinical genomics of advanced prostate cancer. Cell 162: 454.

Robinson D, Van Allen EM, Wu YM, Schultz N, Lonigro RJ, Mosquera JM, Montgomery B, Taplin ME, Pritchard CC, Attard G, et al. 2015b. Integrative clinical genomics of advanced prostate cancer. Cell 161: 1215-1228.

Roos WP, Thomas AD, Kaina B. 2016. DNA damage and the balance between survival and death in cancer biology. Nat Rev Cancer 16: 20-33.

Ryan S, Jenkins MA, Win AK. 2014. Risk of prostate cancer in Lynch syndrome: A systematic review and meta-analysis. Cancer Epidemiol Biomarkers Prev 23: 437-449. 
M.J. Schiewer and K.E. Knudsen

Saad F, Fizazi K. 2015. Androgen deprivation therapy and secondary hormone therapy in the management of hormone-sensitive and castration-resistant prostate cancer. Urology 86: 852-861.

Sandhu SK, Schelman WR, Wilding G, Moreno V, Baird RD, Miranda S, Hylands L, Riisnaes R, Forster M, Omlin A, et al. 2013. The poly(ADP-ribose) polymerase inhibitor niraparib (MK4827) in BRCA mutation carriers and patients with sporadic cancer: A phase 1 dose-escalation trial. Lancet Oncol 14: 882-892.

Saunders EJ, Dadaev T, Leongamornlert DA, Al Olama AA, Benlloch S, Giles GG, Wiklund F, Gronberg H, Haiman CA, Schleutker J, et al. 2016. Gene and pathway level analyses of germline DNA-repair gene variants and prostate cancer susceptibility using the iCOGS-genotyping array. Br J Cancer 114: 945-952.

Scarbrough PM, Weber RP, Iversen ES, Brhane Y, Amos CI, Kraft P, Hung RJ, Sellers TA, Witte JS, Pharoah P, et al. 2016. A cross-cancer genetic association analysis of the DNA repair and DNA damage signaling pathways for lung, ovary, prostate, breast, and colorectal cancer. Cancer Epidemiol Biomarkers Prev 25: 193-200.

Schiewer MJ, Goodwin JF, Han S, Brenner JC, Augello MA, Dean JL, Liu F, Planck JL, Ravindranathan P, Chinnaiyan AM, et al. 2012. Dual roles of PARP-1 promote cancer growth and progression. Cancer Discov 2: 1134-1149.

Schiewer MJ, Knudsen KE. 2014. Transcriptional roles of PARP1 in cancer. Mol Cancer Res 12: 1069-1080.

Shipley WU, Seiferheld W, Lukka HR, Major PP, Heney NM, Grignon DJ, Sartor O, Patel MP, Bahary JP, Zietman AL, et al. 2017. Radiation with or without antiandrogen therapy in recurrent prostate cancer. $N$ Engl J Med 376: 417428.

Siegel RL, Miller KD, Jemal A. 2017. Cancer statistics, 2017. CA Cancer J Clin 67: 7-30.

Tarish FL, Schultz N, Tanoglidi A, Hamberg H, Letocha H, Karaszi K, Hamdy FC, Granfors T, Helleday T. 2015. Castration radiosensitizes prostate cancer tissue by impairing DNA double-strand break repair. Sci Transl Med 7: 312re311.

Taylor BS, Schultz N, Hieronymus H, Gopalan A, Xiao Y, Carver BS, Arora VK, Kaushik P, Cerami E, Reva B, et al. 2010. Integrative genomic profiling of human prostate cancer. Cancer Cell 18: 11-22.

Taylor RA, Fraser M, Livingstone J, Espiritu SM, Thorne H, Huang V, Lo W, Shiah YJ, Yamaguchi TN, Sliwinski A, et al. 2017. Germline BRCA2 mutations drive prostate cancers with distinct evolutionary trajectories. Nat Commun 8: 13671 .
Telli ML, Timms KM, Reid J, Hennessy B, Mills GB, Jensen KC, Szallasi Z, Barry WT, Winer EP, Tung NM, et al. 2016. Homologous recombination deficiency (HRD) score predicts response to platinum-containing neoadjuvant chemotherapy in patients with triple-negative breast cancer. Clin Cancer Res 22: 3764-3773.

Tennant DA, Duran RV, Boulahbel H, Gottlieb E. 2009. Metabolic transformation in cancer. Carcinogenesis 30: 1269-1280.

Tomlins SA, Alshalalfa M, Davicioni E, Erho N, Yousefi K, Zhao S, Haddad Z, Den RB, Dicker AP, Trock BJ, et al. 2015. Characterization of 1577 primary prostate cancers reveals novel biological and clinicopathologic insights into molecular subtypes. Eur Urol 68: 555-567.

Tomlins SA, Rhodes DR, Perner S, Dhanasekaran SM, Mehra R, Sun XW, Varambally S, Cao X, Tchinda J, Kuefer R, et al. 2005. Recurrent fusion of TMPRSS2 and ETS transcription factor genes in prostate cancer. Science 310: 644-648.

Tubbs A, Nussenzweig A. 2017. Endogenous DNA damage as a source of genomic instability in cancer. Cell 168: 644656.

Wang M, Li Q, Gu C, Zhu Y, Yang Y, Wang J, Jin L, He J, Ye D, Wei Q. 2016. Polymorphisms in nucleotide excision repair genes and risk of primary prostate cancer in Chinese Han populations. Oncotarget 8: 24362-24371.

Warde P, Mason M, Ding K, Kirkbride P, Brundage M, Cowan R, Gospodarowicz M, Sanders K, Kostashuk E, Swanson G, et al. 2011. Combined androgen deprivation therapy and radiation therapy for locally advanced prostate cancer: A randomised, phase 3 trial. Lancet 378: 2104-2111.

Widmark A, Klepp O, Solberg A, Damber JE, Angelsen A, Fransson P, Lund JA, Tasdemir I, Hoyer M, Wiklund F, et al. 2009. Endocrine treatment, with or without radiotherapy, in locally advanced prostate cancer (SPCG-7/ SFUO-3): An open randomised phase III trial. Lancet 373: 301-308.

Williams AB, Schumacher B. 2016. p53 in the DNA-damage-repair process. Cold Spring Harb Perspect Med 6: a026070.

Yang B, Chen WH, Wen XF, Liu H, Liu F. 2013. Role of DNA repair-related gene polymorphisms in susceptibility to risk of prostate cancer. Asian Pac J Cancer Prev 14: 5839-5842.

Zannini L, Delia D, Buscemi G. 2014. CHK2 kinase in the DNA damage response and beyond. J Mol Cell Biol 6: 442-457. 


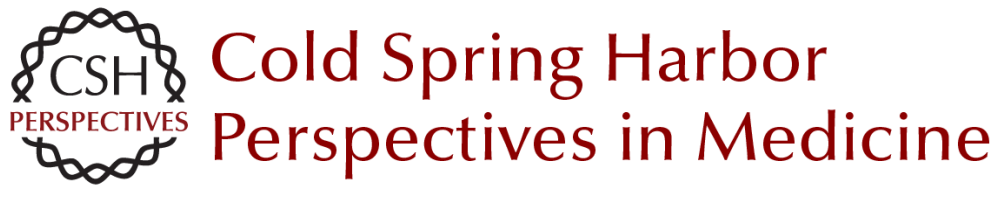

\title{
DNA Damage Response in Prostate Cancer
}

\author{
Matthew J. Schiewer and Karen E. Knudsen
}

Cold Spring Harb Perspect Med 2019; doi: 10.1101/cshperspect.a030486 originally published online March 12, 2018

\section{Subject Collection Prostate Cancer}

Anatomic and Molecular Imaging in Prostate Cancer

Eric T. Miller, Amirali Salmasi and Robert E. Reiter

The Epidemiology of Prostate Cancer Claire H. Pernar, Ericka M. Ebot, Kathryn M. Wilson, et al.

Prostate Stem Cells and Cancer Stem Cells Jia J. Li and Michael M. Shen

Prostate Cancer Epigenetics: From Basic Mechanisms to Clinical Implications Srinivasan Yegnasubramanian, Angelo M. De Marzo and William G. Nelson

\section{The Genomics of Prostate Cancer: A Historic Perspective Mark A. Rubin and Francesca Demichelis}

Neuroendocrine Differentiation in Prostate

Cancer: Emerging Biology, Models, and Therapies Loredana Puca, Panagiotis J. Vlachostergios and Himisha Beltran

DNA Damage Response in Prostate Cancer Matthew J. Schiewer and Karen E. Knudsen

Transcriptional Regulation in Prostate Cancer David P. Labbé and Myles Brown
New Opportunities for Targeting the Androgen Receptor in Prostate Cancer Margaret M. Centenera, Luke A. Selth, Esmaeil Ebrahimie, et al.

Prostate Cancer Research at the Crossroads Michael M. Shen and Mark A. Rubin

Immunotherapy for Prostate Cancer Nicholas J. Venturini and Charles G. Drake

Molecular Pathology of High-Grade Prostatic Intraepithelial Neoplasia: Challenges and Opportunities Levent Trabzonlu, Ibrahim Kulac, Qizhi Zheng, et al.

Metastases in Prostate Cancer Federico La Manna, Sofia Karkampouna, Eugenio Zoni, et al.

Genetically Engineered Mouse Models of Prostate Cancer in the Postgenomic Era Juan M. Arriaga and Cory Abate-Shen

Molecular Biomarkers in the Clinical Management of Prostate Cancer Aaron M. Udager and Scott A. Tomlins

Metabolic Vulnerabilities of Prostate Cancer: Diagnostic and Therapeutic Opportunities Giorgia Zadra and Massimo Loda

For additional articles in this collection, see http://perspectivesinmedicine.cshlp.org/cgi/collection/ 